stainability with this dye of salivary gland chromosomes after prolonged hydrolysis is probably also due to the removal of nucleic acid residues during hydrolysis.

Aceto-carmine smearing is a well-known cytological technique. But the differentiation of the chromosome is thereby often not so good, due to the interference of the stainable components present in cytoplasm. From our experience, it can be suggested that such a difficulty may be easily overcome through a three-minutes hydrolysis in $N$ hydrochloric acid at $50-60^{\circ} \mathrm{C}$., since most of the nucleic acic or its derivatives can be removed from those cellular components other than chromosomes after this mild hydrolysis.

I wish to acknowledge my indebtedness to Dr. M. Dixon for his gift of a sample of yeast nucleic acid through the Sino-British Science Co-operation Office organized by $\mathrm{Dr}$. J. Needham, to whom my sincere thanks are also due.

Ј. Сно.

Department of Biology

National University of Chekiang, Meitan, Kweichow.

Dec. 12.

' Bauer, H., Z. Zellforsch. mikros. Anat., 15, 225 (1932). Hillary, B. B., Bot. Gaz., 101, 276 (1939).

${ }^{2}$ Chu, J., and Pai, S., Nature, 155, 482 (1945).

Abnormal Precipitation of Proteins from Antitoxic Horse Plasma in the Presence of Phenolic Compounds

MosT of the work that has been carried out on the effect of phenol and similar antiseptics on antitoxic plasma has been summarized by Marrack ${ }^{1}$ and deals largely with the destruction of the antitoxin by
concentrations normally used for antiseptic purposes $(0 \cdot 3-0 \cdot 5$ per concent).

Apart from the Imray patent ${ }^{2}$, where high concentrations of phenol were used as a bactericide, there seems to have been little work carried out with antitoxic plasma on the effect of concentrations of antiseptics higher than those normally used for asepsis.

If antitoxic hórse plasma is treated with increasing concentrations
ing of ammonium sulphate the proteins are normally precipitated in the order: flbrin, globulins and albumin. If, however, the precipitation is carried out in the presence of 2.0 per cent phenol or 1.0 per cent tricresol, the albumin is precipitated by low concentrations of ammonium sulphate, and its precipitation occurs before the globulins are precipitated. This is illustrated by the accompanying curves showing the precipitation of antitoxin and protein from antitoxic horse plasma (diphtheria) diluted with: (1) an equal volume of water; (2) an equal volume of 2.0 per cent tricresol in water.

The brown pigments normally associated with the albumin are also precipitated with it, and we can obtain, by a single precipitation with ammonium sulphate, almost colourless solutions of the globulins.

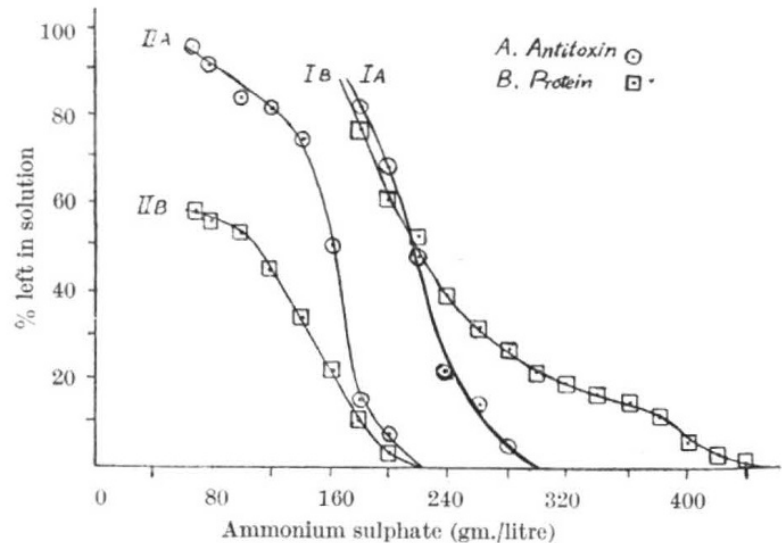

Fig. 1.

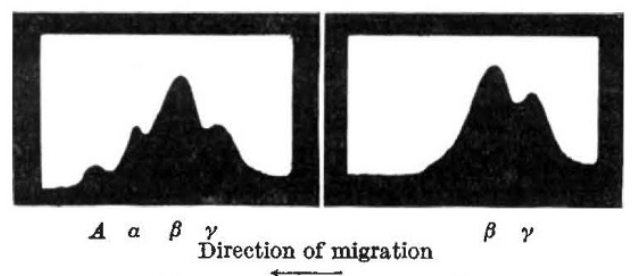

Fig. 2. Electrophoretic diagrams. Descending (CATHOde)

(2)

1. Without tricresol. IMB EXPOSURES.

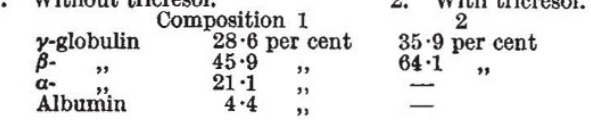

The above observations have led to an improved method for concentrating antitoxic sera, since it is possible by a single precipitation with ammonium sulphate to obtain a solution consisting almost completely of beta and gamma globulins, which have associated with them a very large proportion of the antitoxin. A further precipitation with ammonium sulphate will separate these globulins from the solution and the resulting precipitate can be dialysed to give concentrated solutions of the antitoxic globulins. These solutions are considerably lighter in colour than those prepared by the normal ammonium sulphate concentration methods, and they also possess the valuable property of remaining clear over long periods. The yield of antitoxin is approximately the same, but the purity is very slightly greater. The above electrophoretic analysis shows the marked difference in composition of the ence For this analysis I am indebted to Mr. Charlwood.

Since very much lower concentrations of ammonium sulphate are Since very much lower concentrations of ammonium sulphate are necessary in the presence of 1.0 per cent tricresol to precipitate the protein containing no antibody, this method can be used for concentrating antibacterial sera, for these antibodies tend to be associated with the lower globulin fractions. It has been found possible to apply organisms: influenza virus type A; B. proteus OX19; H. pertussis; bacillus of swine erysipelas.

Other similar compounds which have behaved in a manner comparable with phenol and tricresol are : ortho-, para- and meta-cresols, parable with phenol and tricresol are : ortho-, para- and meta-cresols,
$o$-chlorphenol and $p$-chlorphenol. Further work is being carried out

For the testing of the antibodies, I am indebted to Mr. A. T. Glenny, For the testing of the antibodies, I am indebted to Mr. A. T. Glenny,
Dr. C. L. Oakley, Mr. A. MacIntyre and Mr. H. Proom of the Wellcome Dr. C. L. Oakley, Mr. A. MacIntyre and Mr. H. Proom of the Wellcome
Physiological Research Laboratories; and to Dr. A. Felix of the Medical Research Council.

Wellcome Physiological Laboratories,

A. J. HARMS.

$$
\begin{gathered}
\text { Langley Court, } \\
\text { Beckenham, Kent. }
\end{gathered}
$$$$
\text { Jan. } 16 .
$$

'Marrack, J. M., "The Chemistry of Antigens and Antibodies" (London: H.M. Stationery Office, 1938).

${ }^{2}$ Brit. Pat. No. $18340 / 1902$.

\section{Digitalis and Voluntary Muscle}

THE following interesting observation has been noted during class experiments on frog nerve-muscle dissections, and has been conflrmed by later experiments. Due to shortages of frogs during the War, it was decided that fresh frogs be used flrst for the official method of assay of digitalis preparations and then for nerve-muscle experiments. Such animals received large doses of digitalis into the ventral lymph sac by way of the thigh muscle as seal, and it is known that these sublethal doses are not readily eliminated.

We were particularly interested in the effect of temperature on the nerve-muscle preparation supported in the normal muscle bath. To demonstrate the effect on the latent period, it was customary to use temperatures of $10^{\circ}, 20^{\circ}, 30^{\circ}$ and $40^{\circ} \mathrm{C}$. When the experiments commenced, it soon became evident that the muscles of these 'digitalis' animals were not standing up to such temperature variations, and
lower values had to be employed to obtain class results. Further lower values had to be employed to obtain class results. Further the recovery period (that is, the time after injection) on this abnormal response. The results, indicated in the accompanying table, although performed on a small number of animals, are fairly conclusive. An approximately equal number of control frogs (that is, uninjected) from the same batches of animals were used to show that the normal nerve-muscle preparation survived temperatures of $40^{\circ}-42^{\circ} \mathrm{C}$., with a small percentage (less than 10 per cent) failing to respond to temperatures greater than $40^{\circ} \mathrm{C}$.

EFFECT OF THE RECOVERY PERIOD ON THE RESPONSE OF THE GASTROCNEMIUS MUSCLE TO TEMPERATURE.

\begin{tabular}{|c|c|c|}
\hline \multirow{2}{*}{$\begin{array}{c}\text { Days after } \\
\text { digitalis injection }\end{array}$} & \multicolumn{2}{|c|}{ Frog nerve-muscle preparations at $36-39^{\circ} \mathrm{C}$. } \\
\hline & Not the normal response & Normal response \\
\hline $\begin{array}{r}1 \\
4 \\
7 \\
10 \\
14 \\
21\end{array}$ & $\begin{array}{r}4 \\
8 \\
15 \\
6 \\
8 \\
0\end{array}$ & $\begin{array}{l}0 \\
1 \\
5 \\
1 \\
2 \\
4\end{array}$ \\
\hline Totals & 41 & 13 \\
\hline
\end{tabular}

More than 50 per cent of those responding abnormally developed rigor: those which did not showed either feeble contraction at rigor; those which did not showed either feeble contraction at make and break or no effect on normal and direct muscular stimulation, with the same strength of stimulus. Alteration in excitability is thus indicated, digitalis apparently lowering the thermal threshold. It should be pointed out there was no correlation with dosage of digitalis in these experiments, and it is quite possible that the survivors above may have had smaller doses of the drug. The animals were all injected between October and January, but there was no uniformity as to the
distribution of sex. All other experiments using the nerve-muscle preparations from 'digitalis' frogs behaved in a normal manner.

College of the Pharmaceutical Society, G. B. WEST. 